\title{
Angioplastia de Veia Ilíaca, Revisão e Primeiras Avaliações
}

\author{
Campos W. ${ }^{1}$ \\ ${ }^{1}$ USP - São Paulo - Brasil. \\ E-mail: camposwalter2@terra.com.br
}

Campos, W. 2013. Angioplastia de Veia llíaca, Revisão e Primeiras Avaliações, p.30. In: Bastos, Francisco Reis. Anais do V Simpósio Internacional de Flebologia [Blucher Medical Proceedings n.1 v.1]. São Paulo: Blucher, 2014 http://dx.doi.org/10.5151/medpro-flebo-SIF_11
Apesar do tratamento ideal de trombose venosa profunda aguda (TVP), há uma grande possibilidade de TVP recorrente e desenvolvimento de síndrome pós-trombótica (SPT) a longo prazo. O grau de recanalização espontânea difere por paciente e pela localização do trombo, 90\% de todas as oclusões fêmoro popliteas recanalizam dentro de 1 ano, no entanto, no caso de uma trombose iliofemoral a recanalização ocorre apenas em uma minoria de casos. Complicações pós-trombóticos ocorrem mais em consequência da trombose iliaco femoral, e as chances de trombose recorrente é maior do que a TVP em uma localização mais distal. A chance de ocorrer na veia iliaca E é maior, devido à compressão da veia ilíaca $E$ pela artéria ilíaca D (Síndrome de Cockett).

É importante identificar os pacientes com maior chance de desenvolver SPT prontamente e tratá-los de modo a evitar os sequelas graves.

Apresentamos experiência inicial de 4 casos com recanalização parcial e estenose crítica que foram submetidos a angioplastia com stent evoluindo com melhora parcial ou total dos sintomas.

Palavaras-chave: trombose venosa profunda, síndrome pós-trombotica, angioplastia venosa, Sindr de Cockett. 